\title{
. JLBSR:- \\ Defining a Role of Amanita phalloides Toxins in Cancer: Research and Therapy
}

\author{
Noor T. Hamdan \\ Biology Department, College of Science, Mustansiriyah University, Baghdad, Iraq (noor.t.hamdan@uomustansiriyah.edu.iq)
}

\begin{abstract}
Despite the progress of diagnostic and therapy, the cancer burden is still rising worldwide. The new chemotherapeutical toxicity to somatic cells and its tolerance to tumor cells illustrates the immediate demand through recent pharmaceutical products with less harmful impacts. The use of natural anticancer products, like $\alpha$-amanitin toxins have reached the cancer field therapy since the separation of Amanita phalloides fungi was performed. Application of Amanita phalloides affects tumor cell activity. It is thought that Amanita phalloides dilutions are recommended for a patient suffering from various cancer types and have no severe side effects resulting from amanita therapy. This review aims to explain the use of the therapeutic potential of $\alpha$-amanitin toxin against different cancer types.
\end{abstract}

Keywords: Amatoxins, Amanita phalloides, cancer therapy

Received: January $30^{\text {th }}, 2021 /$ Accepted: March $10^{\text {th }}, 2021 /$ Online: March $19^{\text {th }}, 2021$

\section{INTRODUCTION}

Cancer is considered as the world second leading cause of death and the most difficult illness to handle (Paul et al., 2013). Globally, despite the advancement of diagnosis and treatment, the incidence of cancer is still increasing. The World Health Organization reports that about 9.6 million new cases of cancer accusing in 2018 are going to rise to 21.3 million by 2030 worldwide (Song et al., 2013).

Many cytotoxic therapies can stop the disease's progression from the tumor, but they are mostly too harmful to normal cells, leading healthy tissues to be in a critical situation (Tripathy and Pradhan, 2013). This restricts their efficacy and their use as chemical therapy and emphasizes the immediate need to produce agents, which reduce adverse effects on normal tissues. To overcome this necessity, the utilizing of mushroom (i.e. $\alpha$ - amanitin) has approached the cancer field and further isolation from amanitin fungi has been practiced (Paul et al., 2013).

The Amanita genus includes approximately 900-1000 agarics species, containing some of the world's most toxic identified mushrooms, and few well-recognized edible species (Berch et al., 2017; Zhang et al., 2015). This genus Amanita accounts for about $95 \%$ of the deaths induced by mushroom toxicity, although the death cap comprising approximately 50\% alone (Beug et al., 2006; Moor- Smith et al., 2019).
The lethal dose of amanita toxin is $0.1 \mathrm{mg} / \mathrm{kg}$ of body weight and so acute toxicity of amanita toxin at 5 to $7 \mathrm{mg}$ dose will occur (Jander et al., 2000). The kidneys absorb the amanita toxin, also its typically not observed until 48 hours after absorption in the plasma (Garcia et al., 2015a). Therefore, immediate clinical action is needed to prevent server complications. Several case series demonstrated increased survival relative to the historical survival level (Jander and Bischoff, 2000).

The main active toxin found in these mushrooms named $\alpha$ amanitin (Rodrigues et al., 2020). Although there are many edible mushrooms in this genus, mycologists dishearten mushroom collectors choosing them for human use, rather than knowledgeable experts. However, in some cultures, Amanita is the main local edible species in the local growing season (Diaz, 2018). The toxicity of lethal Amanita mushrooms are distinguished by non-striated and nonappendiculated pilei, attenuated lamellulae, constant annulus presence, a base of bulbous stipe, and volva limbate and basidiospores amyloid shape (Escudié et al., 2007; Cai et al., 2016). Among them, the most deadly toxic mushroom species identified today are Amanita phalloides (zert. Riede), the death cap, resulting in $90-95 \%$ of all overall mushroom toxicity deaths (Figure 1) (Santi et al., 2012; Garcia et al., 2015b). Cholera-like signs accompanied by diarrhea, nausea and vomiting starting 10-20

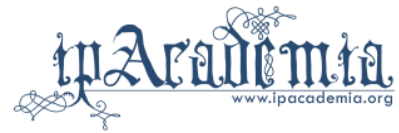


$\mathrm{h}$ after ingestion, then hepatitis, renal failure and subsequent death (Kieslichova et al.,2018; Horowitz and Moss, 2020). The main death toxins in chosen Amanita species include amino acids and cyclopeptides. In addition, isoxazoles are considered as toxic substances, which cause hallucinogenic symptoms present inside some Amanita genera (Zilker and Faulstich, 2017; Yin et al., 2019). The toxic compounds in Amanita phalloides are resistant to temperature, therefore not influenced by cooking (Pulman et al., 2016; Loizides et al., 2018).

A. phalloides mushroom toxicity is associated with two main toxins: amatoxins and phallotoxins. Phallotoxins are less toxic because they degraded quickly by heat and digestion. Amatoxins are considerably more important substances that induce clinical poisoning and have 10 to 20 times higher toxicity than phallotoxins (May et al., 2008; Yilmaz et al., 2015).

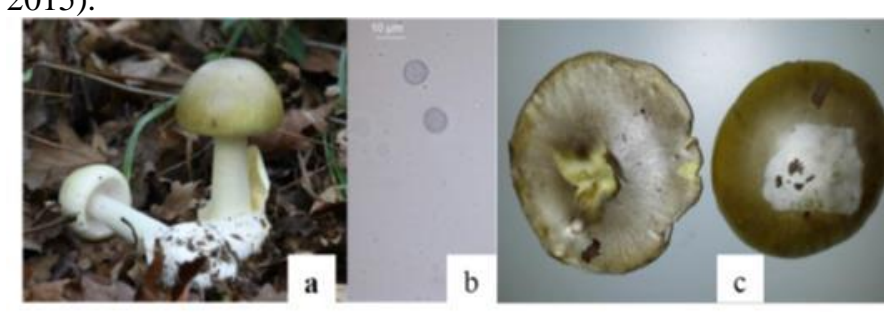

Figure 1. Amanita phalloides (a) amyloid spores and fruit body, (b) spores and (c) on the left ripe mature mushroom and on the right ripe young mushroom (Yilmaz et al., 2015).

Cell destructive therapies such as chemotherapy and utilizing cellular apoptosis induction programs are not yet effective in prolonging a patients life. This is attributed to the tumor cells' resistance to several therapies, and their genetic failure to cause apoptosis (Rodrigues et al., 2020). In the traditional context, $A$. phalloides utilized to overcome the death risk. In a molecular context, newly discovered of this extraction has properties to suppress tumor cells formation.

There are limited information on $\alpha$-amanitin therapy or a combination of $\alpha$-amanitin and chemical substances, for example, recently Amanita phalloides were used for cancer therapy after a German scientist, Isolde Riede, began supporting cancer patients with a homeopathic formulation of Amanita with remarkable success.

The first case study on cancer patients was reported in German 2009 and was revealed a great change with breast cancer patients after Amanita therapy (Riede, 2009).

Moreover, Technique using a monoclonal anti-EPCAM antibody combined with $\alpha$-amanitin as a cancer immunotherapy. Moldenhauer et al., (2012) showed strong growth inhibition impacts on the individual pancreatic cancer without adverse effects at $0.1 \mathrm{mg} / \mathrm{kg}$ dose.

Another study published by Kume et al, (2016) about combination therapy of $\alpha$-amanitin ( $\alpha$-AMA) and cisplatin (CIS) represents a vital process in the elimination of peritonitis carcinomatosa (PC). Liu et al., (2015) focused on the efficacy of antibody-drug conjugates (ADCs) based on alpha-amanitin, which were then targeted at the POLR2A gene. It was observed that when the tumor suppressor gene,
TP53, is deleted, the nearby POLR2A was also deleted and stopped cancer cell growth in mouse models of colorectal cancer.

A recent study of Amanita phalloides inhibits the growth of squamous cells carcinoma (SCC). A patient with pharyngeal SCC is treated with Amanita toxins after failure of conventional treatments with operations and radiations: The state of the patient with SCC can be stabilized for five years. Two years after beginning Amanita, Borrelia infection is diagnosed, and additional treatment with Terebinthina laricina occurs. The dose of Amanita can be reduced after three years of treatment, indicating a reduction of tumor cells (Riede, 2019).

Amanitin is RNA polymerase II (RNAPII) inhibitor in cells within the extract of Amanita. RNAPII is utilized by overexpression of switch genes that use RNAPII to $100 \%$ in tumor cells. Fifty percent of RNAPII inhibition decreases the activity of the tumor cells with no side effects. The immune system can identify tumor cells and attack them thereby opening up the prospect of recovery of healing and stabilization. Amanita therapy may control a range of tumor syndromes (Riede, 2012a, 2013a). This review focuses, therefore on natural treatment strategies to treat cancer by using the application of amanitin therapy.

\section{AMATOXIN PROPERTIES}

Amatoxin occurs as a heat-stable toxin for biochemical categorization, which helps to preserve its three-dimensional form at high temperatures. The enhanced toxicity of amatoxins is because they are not responsive to enzymatic hydrolysis. There are many subtypes of amatoxins, with commonly alpha- amanitin (C39 H54 N10 O14 S, M=918.9) and beta- amanitin (C39 H53 N9 O15 S, M=919.9), and both subtypes are not water-soluble as seen in figure (2) (Bever et al., 2020).

There are not thermosensitive, which means they cannot be destroyed by either cooking or freezing the mushrooms. Moreover, they are gastroresistant (Garcia et al., 2015b) and their metabolism is currently unknown.

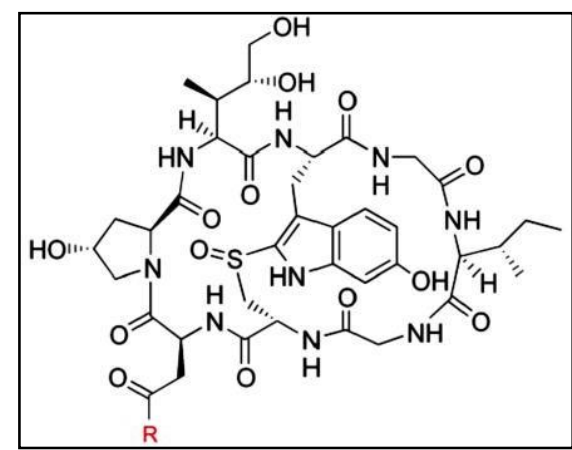

Figure 2. Structure of amatoxins. $\mathrm{R}=\mathrm{NH} 2$ for $\alpha$-amanitin, $\mathrm{R}=\mathrm{OH}$ for $\beta$ amanitin (Bambauer et al., 2020.)

Amatoxins consist of eight toxic substances of eight aminoacid derivatives grouped in a preserved pentacyclic 
configuration as shown in Figure (3) (Pahl et al., 2018).

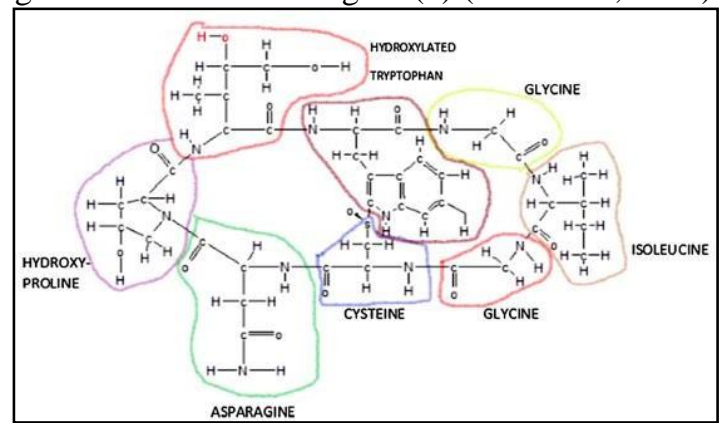

Figure 3. The chemical structure of $\alpha$-Amanitin in which eight amino acids of $\alpha$-amatoxins observed (Litten,1975)

a-Amanitin is a bicyclic octapeptide with a 6hydroxytryptathionine-(R)-sulfoxide cross-link and the oxidized amino acids, 4,5-dihydroxy-isoleucine and trans-4hydroxy-proline (Matinkhoo et al., 2018).

Alpha-amanitin, the most deadly human amatoxin that prevents protein synthesis that irreversibly binds to RNA polymerase II and leads to cell death (Moor-Smith et al., 2019).

\section{ToXic Aspect AND The Harmal EFFects CAUSED BY AMATOXIN}

In the new classification, the amatoxins are classified in the cytotoxic group (1A) (White et al., 2019) as they are responsible for inhibiting RNA polymerase II and the transcription of DNA into RNA by interfering with messenger RNA. This brings about inhibition of protein synthesis, that causes to cell necrosis (Edward et al., 2020). The first cells to be affected are those with a maximum level of protein synthesis like enterocytes, hepatocytes and proximal renal cells (Wieland, 1983). Studies in mice show that renal lesions only occur in poisoning with low levels of amatoxins. In poisoning cases with high levels, the subject die due to acute liver failure or hypoglycemia before the renal lesions appear (Fiume et al., 1969; Faulstich, 1979). Amatoxins are mainly eliminated in the bile, but there is an enterohepatic cycle, which prolongs the hepatoxic action (Broussard et al., 2001). Several studies show that the LD50 of $\alpha$-amanitin in humans is registered to be $0.1 \mathrm{mg} / \mathrm{kg}$ per os (Brüggemann et al., 1996).

Bearing in mind that a sporophore of Amanita phalloides $(20-25 \mathrm{~g})$ can contain $5-8 \mathrm{mg}$ of amatoxins (Faulstich, 1980), the ingestion of one A. phalloides mushroom is theoretically a lethal dose for a $75 \mathrm{~kg}$ man. Toxicity cases of amanita poisoning were recorded with an intake of 30 grams of A. phalloides (Yilmaz et al., 2015).

Recently, (De Olano et al., 2020) estimated of $8.8 \%$ lethal rate of recorded amatoxin toxic cases $(n=148)$ from 2008 to 2018 in the US, whereas registered $11.8 \%(1990-2008 ; n=93)$ in Portugal and under 20\% (1994-2012; $\mathrm{n}=624)$ in South China (Diaz., 2018).

The same order of magnitude as found in mice in a study published by Wieland in 1959 (Wieland, 1959) (LD50 = 0.1 $\mathrm{mg} / \mathrm{kg}$ for $\alpha$-amanitin and $0.4 \mathrm{mg} / \mathrm{kg}$ for $\beta$-amanitin by intraperitoneal injection). Finally, it has been shown that the concentration of amatoxins in the mushroom increases during the first stages of the mushroom's development, then decreases during the mature stage (Hu et al., 2012). No specific antidote exists for the amanitins. Treatment is symptomatic (dialysis, activated charcoal hemoperfusion, glucose/saline perfusion,etc.) (Wauters et al., 1978; Klein et al., 1989). Only kidney or liver transplantation (depending on the symptoms) can save a patient with multiple organ failure (Klein et al., 1989; Meunier et al., 1995). Some authors propose treatments such as thioctic acid (alpha lipoic acid) (Kubicka, 1968; Becker et al., 1976., Rodrigues et al., 2017), penicillin G (Moroni, et al., 1976), or silibinin (Baumgärtner et al., 2011), which may be capable of limiting, if not inhibiting, the amatoxins' penetration into the liver cells and/or interrupting the enterohepatic cycle of the toxins (Enjalbert et al., 2002). However, these treatments have not really been clinically proven and there is no signs for using penicillin $G$ or of thioctic acid. They are therefore not considered as part of the protocol for treatment of amanitin poisoning.

It seems clear that infants and small children are more sensitive to these amanitin poisoning than adults, probably because of their lower body mass: the same dose of toxins ingested will be more toxic and the percentage of fatalities will be higher in young subjects (Flament et al., 2020).

\section{CANCER THERAPY WITH AMANITA TOXINS (AMANITIN)}

During the last years, there was an increasing in the number of studies that deals with the identification of as possible cancer treatment by the injection of fungus toxic substances directly into the tumor. It was mentioned, for example, the therapy of Amanita is provided as dilutions of A. phalloides. Their dilutions have been used for 300 years and a classical homoeopathical sign of apprehension of death. Approximately $50 \%$ of all RNAP molecules in $100 \mathrm{ml}$ dilutions of $A$. phalloides $\mathrm{D} 2$, are inhibited within all cells. Thus, the patient is typically stabilized for years with varying doses (Riede, 2016).

Numerous HOX genes, named switch genes, have been enhanced by molecular events that induce tumor formation, which coded for RNA polymerase II transcription factors (Riede, 2013a). Therefore, RNA polymerase II is most effective in tumor cells than elsewhere. Amanitin extract inhibits RNA polymerase II via an inhibition of mRNA mechanism, leading to several types of tissue harms, especially in intestinal mucosa, liver and kidneys. The toxin is transferred to these tissues by enterohepatic circulation accompanied by renal reabsorption (Riede, 2013a; Garcia et al., 2015c). 


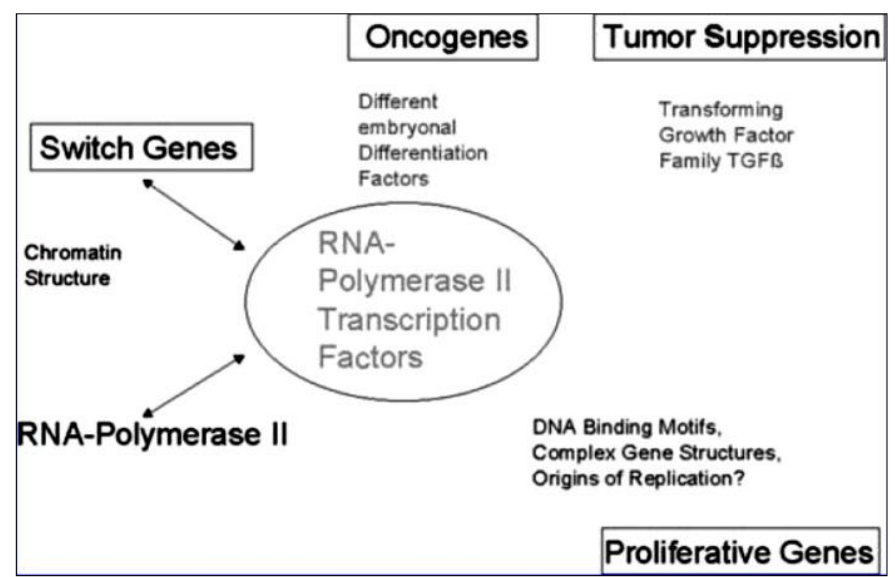

Figure 4. Tumor formation biochemistry (Riede, 2013a). All switch genes acts as transcription factors for RNA polymerase II (RNAP) and cause to be $100 \%$ activity of RNAP in tumor cells. Partial inhibition of activity reduces tumor cell activity with no influencing normal cells.

Partial inhibition of this enzyme induces tumor-cell response inhibition, without extreme effects to somatic cells. The compound amanitin inhibits RNAP in all cells. Approximately $50 \%$ of molecule inhibition has little impact on human body cells (Riede, 2007).

To expand the therapeutic range, dilutions of amanitin in $A$. phalloides extract are given to a patient (Riede, 2010).

Amanita therapy stabilizes numerous tumor diseases successfully:

\section{A. Mammary Duct Cancer}

Amanitin dilutions from $A$. phalloides are added to a patient with mammary duct cancer. Various amanitin doses are used for the detection of tumor markers. The previous tumorgrowth duplication period is three months. Nevertheless, the patient could be recovered within 18 months, without further tumor growth. There are still no significant signs, no hepatic disruption and no continued deprivation of erythrocytes. This latest tumor treatment principle demonstrates a strong potential for medical treatment by using A. phalloides dilutions (D2, D4) (Riede, 2011).

\section{B. Leukemia}

Leukemia tends to be commonly reported as anaemia disease, i.e. erythrocytes absence. The leukocyte tumor growth destroys the bone marrow, especially the erythropoietic stem cells, which contributes to the depletion of erythrocytes. A recent tumor therapy theory is introduced to this research: Amanitin therapy. The amanitin retarded the tumor cells activity. Monitoring leukocyte appearance contributes to dosing in the blood. When the number of cells rises and the patients overall health is well, a maximum dosage is added and vice versa. Each maximum dose interval (i.e., $80 \mathrm{ml}$ of D2 within several months) began with low levels of erythrocytes (Riede, 2010).

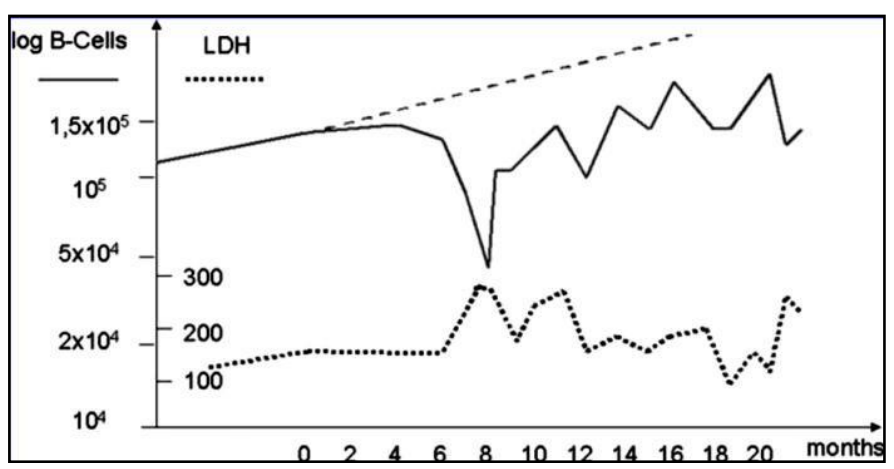

Figure 5. B-cell chronic lymphatic leukemia (B-CLL) treatment (Riede, 2010). The levels of the leukocyte cell numbers in blood (Log B-cells [/mL blood]) over time (solid line). Before amanita therapy, the cells observed slowly growth at 21 months duplication period (elongated as broken line). Amanita therapy began at time zero. Lactate dehydrogenase (LDH) levels (dotted line) vary with leukocyte levels. When a maximum dose is given, leukocyte levels declines and LDH levels go up, meaning tumor cells lysis.

Due to amanitin uptake, the numbers of leukocytes reduces in the blood and certain cells lysis rises lactate dehydrogenase (LDH). This repeatedly helps in the erythrocyte level recovery in a short period within the blood. In the absence of amanitin, the LDH values stay in the appropriate range, suggesting that the immune system does not lysis tumor cells effectively. With amanitin uptake, the count of leukocyte cells rises, and cell lysis occurs, this means the tumor leukocytes is possibly lysis. This lysis indicates that amanitin is not only can disrupt the tumor growth activity, but may also modify the expression of antigen, which may make the immune system more effective to destroy the tumor cells (Riede, 2015). After the starting of therapy for eight months, the leukocyte count decreases to $0.45 \times 10^{5} / \mu 1$, correlating with lymphocytic inflammatory signs. Then, the leukocyte value rises to $1.08 \times 10^{5} / \mu 1$ within one week. This duplication is not supposed to occur from cell growth; the period for duplication is 21 months. Additionally, leukocyte migration is also mentioned. Probably, the leukocyte count declines in blood, which may not only from cells lysis, but also from periphery migration. Therefore, Amanitin can affect the leukocytes migration, as seen in Figure 3 (Riede, 2010). About 1-00ml of A. phalloides D2 annually will arrested BCLL tumor growth. Amanita therapy frequently has good therapeutic or prophylactic results in a number of other tumors, including mammary carcinoma, tongue root tumor and colon carcinoma (Riede, 2007). The somatic cells activity, particularly the immune cells, are not affected by this therapy. Amanitin inhibits the tumor cells activity, and then it lyses and migrates. Therefore, A. phalloides homoeopathic dilutions provide good cancer treatment tools (Riede, 2010, 2015).

\section{Colon Carcinoma and Thyroid Carcinoma}

Amanita therapy and dietary patterns appear to give several patients new possibilities. Changing dietary patterns by adding 70 gram sugar daily results in increased tumor marker values. The tumor marker values decline after diet without sugar and decreased carbohydrates. Despite amanita tumor therapy with sugar, the tumor activity increases; hence, low 
dietary carbohydrates help the therapy. Therefore, amanita therapy as a lifelong treatment is recommended. Scientific research suggests a balanced cancer- protecting diet. Some regimens utilize a diet with reduced carbohydrate comprising unprocessed materials (Riede, 2013b).

The sugar consumption effect on tumor cell activity may be observed by monitoring tumor markers. Although the thyroid cancer cells are less affected, rectal tumor cells show a triple increase in their activity. A supportive dietary is used as cancer protection and cancer patients such as vegetables, fruits, wild herbs, rich unsaturated fatty acids and plant oils (Riede, 2013b).

\section{Prostate Cancers}

Prostate cancer is considered one of the most common cancers among men, which appears over fifty. The signs, physical examination, prostate-specific antigen (PSA), or biopsy can be recommended for diagnosis (Riede, 2017). Prostate cancer screening is addressed among men older than 50. The dilutions of $A$. phalloides (D2, D4), partially very little dose i.e., some D4 drops per day, are adequate to maintain PSA levels. In 2010, fear of the tumor contributes to voluntary of amanita uptake. After three years from using therapy, all three patients began feeling well and they avoided taking amanita. The patients may ignore it in order to maintain a low serum level, PSA values increase and involve $100 \mathrm{ml}$ of D2 intake in two months (Riede, 2012b).

Amanitas long-term desire for physical symptoms needs a good leadership. Further research will show more facets of this latest possibility (Riede, 2012b, 2016).

\section{V.CONCLUSIONS}

In recent years, $\alpha$-amanitin of amanita therapy received an increased attention as a gentle medical treatment in cancer therapy is more suitable. Through my readings to different researchers' reports, no severe side effects happen and no clinical symptoms when the patient used the amanita therapy. Amanitin inhibits the activity of tumor cells. Thus, $\alpha$-amanita can first be used as a tumor-specific therapy. Antiandrogen drugs, chemical therapy, radiation or prostatectomy can be used at subsequent levels.

\section{CONFLICT OF INTEREST}

The author declares no conflict of interest.

\section{ACKNOWLEDGEMENTS}

The author would like to thank Mustainsiriyah University (www.uomustansiriyah.edu.iq) Baghdad, Iraq for its support in the present work.

\section{REFERENCES}

Bambauer, T.P., Wagmann, L., Weber, A.A., and Markus, R. M. (2020). Analysis of $\alpha$ and $\beta$-amanitin in Human Plasma at Subnanogram per Milliliter Levels by Reversed Phase Ultra- High Performance
Liquid Chromatography Coupled to Orbitrap Mass Spectrometry. Toxins, $12,671$.

Baumgärtner, E., Schyska, R., Binscheck, T. (2011). Analyzing the diagnostic value of Amatoxin-ELISA in mushroom poisoning. Clin. Toxicol, 49.

Becker, C.E., Tong, T.G., Boerner, U. (1976). Diagnosis and Treatment of Amanita Phalloides-Type Mushroom Poisoning: Use of Thioctic Acid. West. J. Med., 125, 100-109.

Berch, SM., Kroeger, P., Finston, I. (2007). The death cap mushroom (Amanita phalloides) moves to a native tree in Victoria, British Columbia., Botany, 95, 435-440.

Beug, B. M., Shaw, M., Cochran, K. (2006). Thirty Plus Years of Mushroom Poisoning: Summary of the Approximately 2000 Reports in the NAMA Case Registry., Mcllvainea, 16,47-68.

Bever, C.S., Swanson, K.D., Hamelin, E.I., Filigenzi, M., Poppenga, R.H., Kaae, J., Cheng, L.W., Stanker, L.H. (2020). Rapid, sensitive, and accurate point-of-care detection of lethal amatoxins in urine. Toxins, 12(2), 123, $10 \mathrm{pp}$.

Broussard, C.N., Aggarwal, A., Lacey, S. (2001). Mushroom Poisoningfrom Diarrhea to Liver Transplantation. Am. J. Gastroenterol., 96, 3195-3198.

Brüggemann, O., Meder, M., Freitag, R. (1996). Analysis of Amatoxins Alpha-Amanitin and Beta-Amanitin in Toadstool Extracts and Body Fluids by Capillary Zone Electrophoresis with Photodiode Array Detection. J. Chromatogr. A., 744, 167-176.

Cai, Q., Cui, Y.Y., Yang, Z.L. (2016). Lethal Amanita species in China. Mycologia, 108(5), 993-1009.

De Olano, J., Wang, J.J., Villeneuve, E., Gosselin, S., Biary, R., Su, M.K., Hoffman, R.S. (2020). Current fatality rate of suspected cyclopeptide mushroom poisoning in the United States. Clin. Toxicol., 1-4.

Diaz, J.H. (2018). Amatoxin-containing mushroom poisonings: Species, toxidromes, treatments, and outcomes. Wilderness Environ. Med., 29(1),111-118.

Edward, T. R., David, R. H., Tom, S., Naomi, E. A., Timothy, P. E. (2020). Hunter's Tropical Medicine and Emerging Infectious Diseases (Tenth Edition), Elsevier, 1006-1020.

Enjalbert, F., Rapior, S., Nouguier-Soulé, J. (2002). Treatment of Amatoxin Poisoning: 20-Year Retrospective Analysis. J. Toxicol. Clin. Toxicol., 40, 715-757.

Escudié, L., Francoz, C., Vinel, JP., Moucari, R., Cournot, M., Paradis, V., Sauvanet, A., Belghiti, J., Valla, D., Bernuau, J. and Durand. F. (2007). Amanita phalloides poisoning: Reassessment of prognostic factor and indications for emergency liver transplanation. J, Hepatol, 46, 466-73.

Faulstich, H. (1979). New aspects of amanita poisoning. Klin. Wochenschr., 57, 1143-1152.

Faulstich, H. (1980). Mushroom Poisoning. Lancet, 2, 794-795.

Fiume, L., Marinozzi, V., Nardi, F. (1969). The Effects of Amanitin Poisoning on Mouse Kidney. Br. J. Exp. Pathol., 50, 270-276.

Flament, E., Guitton, J., Gaulier J-M, Gaillard Y. (2020). Human Poisoning from Poisonous Higher Fungi: Focus on Analytical Toxicology and Case Reports in Forensic Toxicology. Pharmaceutical, 454, 12 (13).

Garcia, J., Costa, VM, Baptista, P., Lourdes Bastos, M., Carvalho, F. (2015a). Quantification of alpha-amanitin in biological samples by HPLC using simultaneous UV- diode array and electrochemical detection. J Chromatogr B Anal Technol Biomed Life Sci, 997, 85-95.

Garcia, J., Costa, VM., Carvalho, A., Baptista, P., de Pinho, P.G., de Lourdes Bastos, M., Carvalho, F. (2015b). Amanita phalloides poisoning: mechanisms of toxicity and treatment. Food Chem Toxicol, 86, 41-55.

Garcia, J., Oliveira, A., de Pinho, P.G., Freitas, V., Carvalho, A., Baptista, P., Pereira, E., de Lourdes Bastos, M., Carvalho, F. (2015c). Determination of amatoxins and phallotoxins in Amanita phalloides mushrooms from northeastern Portugal by HPLCDAD-MS. Mycologia, 107(4), 679-687.

Horowitz, B.Z., Moss, M.J. (2020). Amatoxin mushroom toxicity. StatPearls Publ., Treasure Island https://www.ncbi.nlm.nih.gov/books/NBK431052. 
Hu, J., Zhang, P., Zeng, J. (2012). Determination of Amatoxins in Differerent Tissues and Development Stages of Amanita Exitialis. J. Sci. Food Agric., 92, 2664-2667.

Jander, S. Bischoff, J., Woodcock, BG. (2000). Plasmapheresis in the treatment of Amanita phalloides poisoning: II. A review and recommendations. Ther Apher., 4(4), 308-312.

Jander, S., Bischoff, J. (2000). Treatment of Amanita phalloides poisoning: I. Retrospective evaluation of plasmapheresis in 21 patients. Ther Apher. 4(4), 303-307.

Kieslichova, E., Frankova, S., Protus, M., Merta, D., Uchytilova, E., Fronek, J. Sper, J. (2018). Acute liver failure due to Amanita phalloides poisoning: Therapeutic approach and outcome. Transplant, Proc, 50, 192-197.

Klein, A.S., Hart, J., Brems, J.J. (1989). Amanita Poisoning: Treatment and the Role of Liver Transplantation. Am. J. Med., 86, 187-193.

Kubicka, J. (1968). Traitement des empoisonnements fongiques phalloidiniens en Tchecoslovaquie [Treatment of phalloidesrelated poisonings in Tchecoslovaquia. Acta Mycol., 4, 373-377.

Kume, K., Ikeda, M., Miura, S., Kume, K., Ikeda, M., Miura, S., Ito, K., Sato, K.A., Ohmori, Y., Endo, F.,Katagiri, H., Ishida, K., Ito, C., Iwaya, T., Nishizuka, S.S. (2016). $\alpha$-Amanitin Restrains Cancer Relapse from Drug-Tolerant Cell Subpopulations via TAF15. Sci Rep 6, 25895.

Litten, W. (1975). The most poisonous mushrooms, Sci. Am., 232, 90-101.

Liu, Y., Zhang, X., Han, C., Wan, G., Huang, X., Ivan, C., Jiang, D., Rodriguez-Aguayo, C., Lopez-Berestein, G., Rao, PH., Maru, DM., Pahl, A., He, X., Sood AK, Ellis, LM., Anderl, J., Lu, X. (2015). TP53 loss creates therapeutic vulnerability in colorectal cancer. Nature, 30, 520(7549), 697-701.

Loizides, M., Bellanger, J.M., Yiangou, Y., Moreau, P.A. (2018). Preliminary phylogenetic investigations into the genus Amanita(Agaricales) in Cyprus, with a review of previous records and poisoning incidents. Documents, Mycologiques., 37, 201218.

Matinkhoo, K., Pryyma, A., Todorovic, M., Patrick, B.O., Perrin, D.M. (2018). Synthesis of the Death-Cap Mushroom Toxin $\alpha$ Amanitin. Journal of the American Chemical, Society., 140, (21), 6513-6517.

May, J.P., Fournier, P., Patrick, B.O., Perrin, D.M. (2008). Synthesis, characterisation, and In vitro evaluation of Pro2-Ile3- S-deoxoamaninamide and Pro2-D-allo-Ile3-S-deoxo- amaninamide: implications for-structure-activity relationships in amanitin conformation and toxicity. Chemistry, 14, 3410- 3417.

Meunier, B.C., Camus, C.M., Houssin, D.P. (1995). Liver Transplantation after Severe Poisoning Due to Amatoxin- Containing LepiotaReport of Three Cases. J. Toxicol. Clin. Toxicol., 33, 165-171.

Moldenhauer, G., Salnikov, A.V., Lüttgau, S., Herr, I., Anderl, J., Faulstich, H. (2012). Therapeutic potential of amanitin-conjugated antiepithelial cell adhesion molecule monoclonal antibody against pancreatic carcinoma. J Natl Cancer Inst., 104, 622-634.

Moor-Smith, M., Li, R., Ahmed, O. (2019). The world's most poisonous mushroom, Amanita phalloides, is growing in BC. B. C. Med. J, 61(1), 20-24.

Moroni, F., Fantozzi, R., Masini, E.A. (1976). Trend in the Therapy of Amanita Phalloides Poisoning. Arch. Toxicol., 36, 111-115.

Pahl, A., Lutz, C., Hechler, T. (2018). Amanitins and their development as a payload for antibody-drug conjugates. Drug Discov Today Technol, 30, 85-89.

Paul, A., Das, S., Das, J., Sammader, A., Khuda-Bukhsh, A.R. (2013). Cytotoxicity and apoptotic signaling cascade induced by chelidonine-loaded PLGA nanoparticles in HepG2 cells In vitro and bioavailability of nano-chelidonine in mice in vivo. Toxicol. Lett., 222(1), 10-22.

Pulman, J.A., Childs, K.L., Sgambelluri, R.M., Walton, J.D. (2016). "Expansion and diversification of the MSDIN family of cyclic peptide genes in the poisonous agarics Amanita phalloides and $A$. bisporigera". BMC Genomics, 17 (1),1038.

Riede, I. (2007). The biochemistry of the tumor cell. Naturheilpraxis, 12, 1733-1743. (In German).

Riede, I. (2009). Amanita Therapie eines Mammakarzinoms. NATURHeilkunde, 32, 18.
Riede, I. (2010). Tumor therapy with Amanita phalloides (death cap): Stabilization of B-cell chronic lymphatic leukemia. J. Altern. Complement Med., 16(10), 1129-1132.

Riede, I. (2011). Tumor therapy with Amanita phalloides (Death Cap): Stabilization of mammary duct cancer. TANG: Intern. J. Genuine Trad. Med., 1(1), 5,1-5.3.

Riede, I. (2012a). Inhibition of apoptosis in ALL-1 leukemic cell lines: Allowance of replication, constant repair replication, defect DNA damage control. J. Cell Sci. Ther., 3(6), 133.

Riede, I. (2012b). Tumor therapy with Amanita phalloides (Death Cap): Long-term stabilization of prostate cancers. J. Integr. Oncol., $1(1), 3-10$.

Riede, I. (2013a). Switch the tumor off: From genes to Amanita therapy. Am. J. Biomed. Res., 1(4), 93-107.

Riede, I. (2013b). Tumor therapy with Amanita phalloides: Remission of a tumor disease and dietary effect of sugar. J. Cell Sci. Ther., 4(3), 1000147, 3 pp.

Riede, I. (2015). Borrelia infection appears as chronic lymphocytic leukemia: Therapy with Amanita phalloides and Terebinthina laricina. $\mathrm{Br}$. J. Med. Med. Res., 7(7), 630-637.

Riede, I. (2016). Stabilization of prostate cancer with Amanita phalloides: Intervals with 5-alpha-reductase inhibitors and melatonin to circumvent resistance: Case report: Br. J. Med. Med. Res., 17(5), $1-6$.

Riede, I. (2017). New therapy strategy for prostate cancer: Amanita phalloides treatment stabilizes best without pre- treatments (observational study pre-protocol). Br. J. Med. Med. Res., 21(3), $1-7$.

Riede. I. (2019). "Amanita phalloides in Tumor Therapy: Stabilization of Pharyngeal Squamous Cell Carcinoma (Case Report)". Acta Scientific Cancer Biology, 3(3), 70-73.

Rodrigues, D.F., Ricardo, P.d.N., Alexandra, T.P.C., Maria, L.Ba., Vendramin, A., Jamsek, M., Brvar, M. (2017). Amanita phalloides poisoning in Slovenia, 1999-2015. Clin. Toxicol., 55, 501.

Rodrigues, D.F., das Neves, R.P., Carvalho, A.T.P., Bastos, M.L., Costa, V.M., Carvalho, F. (2020). In vitro mechanistic studies on $\alpha$ amanitin and its putative antidotes. Arch. Toxicol., 94, 20612078.

Santi, L., Maggioli, C., Mastrorobeerto, M., Tufoni, M., Napoli, L., Caraceni, P., (2012). Acute Liver Failure Caused by Amanita phalloides Poisoning. Int J Hepatol., 31,480-487.

Song, F.Q., Liu, Y., Kong, X.S., Chang, W., Song, G. (2013). Progress on understanding the anticancer mechanisms of medicinal mushroom: Ínonotus obliquus. Asian Pac. J. Cancer Prev., 14(3), 1571-1578.

Tripathy, G., Pradhan, D. (2013). Evaluation of in-vitro anti- proliferative activity and in-vivo immunomodulatory activity of Beta vulgaris. Asian J. Pharm. Clin. Res., 6(Suppl. 1), 127-130.

Wauters, J.P., Rossel, C., Farquet, J.J. (1978). Amanita Phalloides Poisoning Treated by Early Charcoal Haemoperfusion. Br. Med. J., 2, 13-20

White, J., Weinstein, S., De Haro, L. (2019). Mushroom Poisoning: A Proposed New Clinical Classification. Toxicon , 157, 53-65.

Wieland, T. (1983). The Toxic Peptides from Amanita Mushrooms. Int. $J$. Pept. Protein Res., 22, 257-276.

Wieland, T., Wieland, O. (1959). Chemistry and Toxicology of the Toxins of Amanita Phalloides. Pharmacol. Rev., 11, 87-107.

Yilmaz, I., Ermis, F., Akata, I., Kaya, E. (2015). A case study: What doses of Amanita phalloides and amatoxins are lethal to humans? Wilderness Environ. Med., 26(4), 491-496.

Yin, X., Yang, A.A., Gao, J.M. (2019). Mushroom toxins: Chemistry and toxicology. J. Agric. Food Chem., 67(18), 5053-5071.

Zhang, P., Tang, L.P., Cai, Q., Xu, J.P. (2015). A review on the diversity, phylogeography and population genetics of Amanita mushrooms. Mycology, 6(2), 86-93.

Zilker, T., Faulstich, H. (2017). Cyclopeptide-containing mushrooms: The deadly Amanitas. In: Brent J, Burkhart K, Dargan P, et al. (eds). Critical care toxicology. 2nd ed; New York: Springer; p. 21292148. 